\title{
A TANDEM FOREARM PLETHYSMOGRAPH FOR STUDY OF ACUTE RESPONSES \\ OF THE PERIPHERAL VEINS OF MAN: THE EFFECT OF EN- VIRONMENTAL AND LOCAL TEMPERATURE CHANGE, AND THE EFFECT OF POOLING BLOOD IN THE EXTREMITIES ${ }^{1}$
}

\author{
By J. EDWIN WOOD² AND JOHN W. ECKSTEIN ${ }^{3}$ \\ (From the Department of Medicine, Boston University School of Medicine, and the Evans \\ Memorial, Massachusetts Memorial Hospitals, Boston, Mass.)
}

(Submitted for publication November 13, 1956; accepted September 19, 1957)

The primary mechanism of action of the smooth muscle of the veins upon their contained blood is one of imparting pressure to the blood by a surrounding force. This mode of action is to be distinguished from that of the smooth muscle of the arterioles, which is one of maintenance of arterial pressure through resistance to the outflow of blood. The function of the arterioles as resistive elements in the circulation is evaluated by the relationship between the volume of the flow of blood through the arterioles per unit period of time and the change in pressure across the arterioles. The function of the veins as containers of the blood volume is best evaluated by the relationship between a change of the volume of the veins and the associated change of the pressure of the veins.

It is the purpose of this paper to describe a new method for the simultaneous study of the functions of the arterioles and the veins of the extremities of man. In addition, the effects of several stimuli upon veins and arterioles of the forearm are also described. The stimuli employed were the reduction of the temperature of the room, the reduction of the temperature surrounding the forearm under study, and the congestion of the veins of the three extremities not being studied.

\section{METHODS}

A water plethysmograph made of lucite which had two chambers was used in all of the experiments (Figure 1). Each chamber was $8.5 \mathrm{~cm}$. long and had separate sleeves which were thin, loose fitting rubber. The

\footnotetext{
1 This study was supported by a grant from the Life Insurance Medical Research Fund.

2 Massachusetts Heart Association Research Fellow.

${ }^{3}$ Special Research Fellow of the National Heart Institute. Present address: Department of Internal Medicine, University Hospitals, Iowa City, Iowa.
}

outer end of each sleeve was everted and attached to a flange at its respective end of the plethysmograph. The inner ends of the two sleeves were attached to the permanent plate that separated the two chambers. Thin ( 3 $\mathrm{mm}$.), rigid plates, held firmly in place, separated the two sleeves in the center of the plethysmograph and came into close apposition with the skin of the forearm. A change of volume in one chamber did not alter the volume of the other chamber. Similar plates also prevented the sleeve from bulging out at the ends of the plethysmograph (1). In effect, the instrument consisted of two short plethysmographs placed in tandem on the forearm.

A pneumatic cuff which was $8 \mathrm{~cm}$. wide was placed on the wrist just beyond the distal end of the plethysmograph. This cuff was inflated to suprasystolic pressure prior to each determination. A pneumatic cuff $12.5 \mathrm{~cm}$. wide was placed on the upper arm several centimeters distant from the proximal end of the plethysmograph. Pressure in this cuff was monitored with a water manometer. Unless stated otherwise, the temperature of the water in the plethysmograph was maintained at $32^{\circ} \mathrm{C}$. The total volume of the forearm segment was determined by the displacement of water from the plethysmograph. Change in volume of the forearm resulted in change in the water level of the plethysmograph. This change of water level was detected with two partially immersed electrodes, constructed as described by Cooper and Kerslake (2), used in conjunction with a Sanborn strain gauge amplifier and a Sanborn direct writing instrument. ${ }^{4}$ The recording system was calibrated by introducing known quantities of water into the plethysmograph. Venous pressure was measured with a Statham P23D strain gauge from a small polyethylene catheter inserted into a forearm vein (Figure 1). Venous pressure was also recorded with the Sanborn direct writing instrument.

The exact relationships between changes of pressure within the forearm veins and the associated changes of volume of these veins were studied as follows: The subject was seated with his forearm in the plethysmograph at heart level. Change of the volume in the proximal

${ }^{4}$ Construction of electrodes and adaptation to Sanborn strain gauge amplifier by Sanborn Company, Waltham, Massachusetts. 


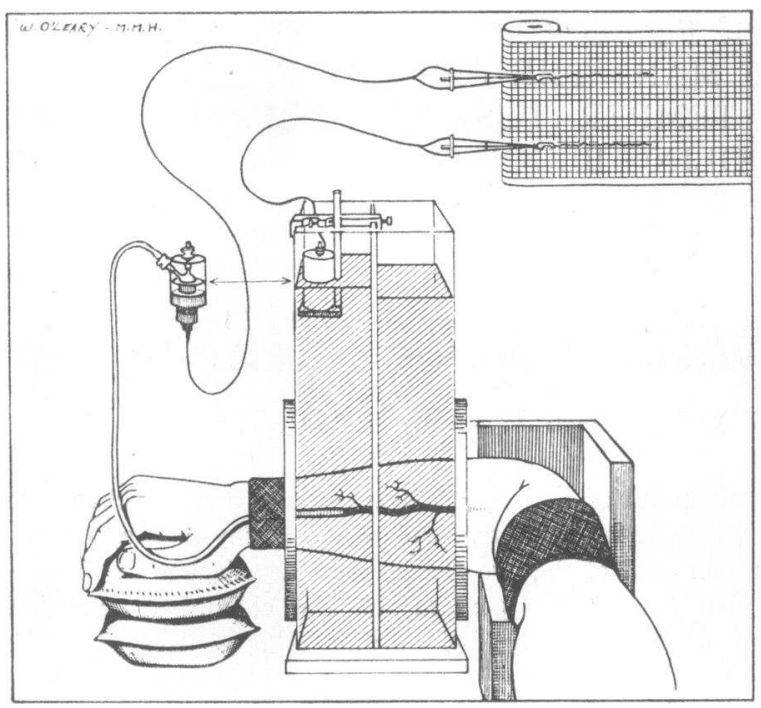

Fig. 1. The Two Chamber Plethysmograph

Strain gauge, venous catheter and water level electrodes also shown.

chamber of the plethysmograph, change of the volume in the distal chamber of the plethysmograph and pressure in a vein in the distal chamber of the plethysmograph were measured simultaneously. Tracings were obtained with and without water in the proximal chamber of the plethysmograph. The water level in the plethysmograph was such that the external hydrostatic pressure exceeded the original venous pressure at the tip of the catheter (without water in the plethysmograph). The original venous pressure at the tip of the catheter, relative to atmospheric pressure, will be referred to hereafter as natural local venous pressure. By placing the membrane of the strain gauge at the level of the water in the distal chamber (Figure 1), the recording obtained was internal venous pressure minus the external hydrostatic pressure at the level of the tip of the catheter (referred to hereafter as the effective venous pressure). The water level in the proximal chamber was kept $3 \mathrm{~mm}$. lower than that in the distal chamber so that it could not of itself congest the veins of the distal segment. Pressure in the cuff on the upper arm was raised by $1 \mathrm{~mm}$. Hg increments until initial pressure and volume changes had occurred. Following this, pressure in the cuff was raised by $5 \mathrm{~mm} . \mathrm{Hg}$ increments for a total of $30 \mathrm{~mm}$. $\mathrm{Hg}$.

All additional venous pressure-volume experiments were performed as follows: Water was added to both chambers of the plethysmograph to a level such that the external hydrostatic pressure was certain to exceed the natural local venous pressure of the subject. This water level $(3 \mathrm{~mm}$. lower in the proximal chamber of the plethysmograph) was maintained throughout each experiment. Change in volume of the distal segment only was then measured. Pressure within the veins of the forearm in the plethysmograph was not measured. Pressure in the proximal cuff was raised above atmos- pheric pressure by $1 \mathrm{~mm}$. $\mathrm{Hg}$ increments until the first small positive deflection in forearm volume (distal segment) occurred. Sudden release of pressure in the cuff resulted in immediate return of the volume of the forearm to its original level unless the rise in volume was artifactual. The cuff pressure relative to atmospheric pressure which was required to produce this change of forearm volume ranged from 15 to $25 \mathrm{~mm}$. $\mathrm{Hg}$ and was referred to as "cuff zero." Cuff pressure was raised further from "cuff zero" by six successive $5 \mathrm{~mm}$. $\mathrm{Hg}$ increments. Forearm volume was allowed to reach a new equilibrium prior to initiation of each increment. The small volume increase produced by "cuff zero" itself was included in the first increment. The volume increments were plotted additively against effective venous pressure (Figure 2). The volume increase in $\mathrm{ml}$. per $100 \mathrm{ml}$. forearm tissue with a rise in effective venous pressure of 30 $\mathrm{mm}$. $\mathrm{Hg}$ was called venous volume [30] (Figure 2).

The effect of sudden venoconstriction upon the volume of the veins when water was in the plethysmograph as above but without pressure in the proximal cuff was investigated, utilizing the method just described. The subject was studied in the recumbent position with the plethysmograph on one forearm and an intravenous saline infusion in the opposite arm. A venous pressurevolume curve was obtained; then pressure in the proximal cuff was released. The volume of the forearm was allowed to stabilize; then the saline infusion was switched to an infusion of 15 to 30 micrograms per minute of norepinephrine base. The record of the volume of the forearm was observed for three minutes after which the measurement of the pressure-volume curve of the veins was repeated and the volume of the forearm reestablished once again. Arterial occlusion at the wrist was maintained through this sequence.

The effects of environmental and local cooling. Normal young male subjects wearing shorts only were stud-

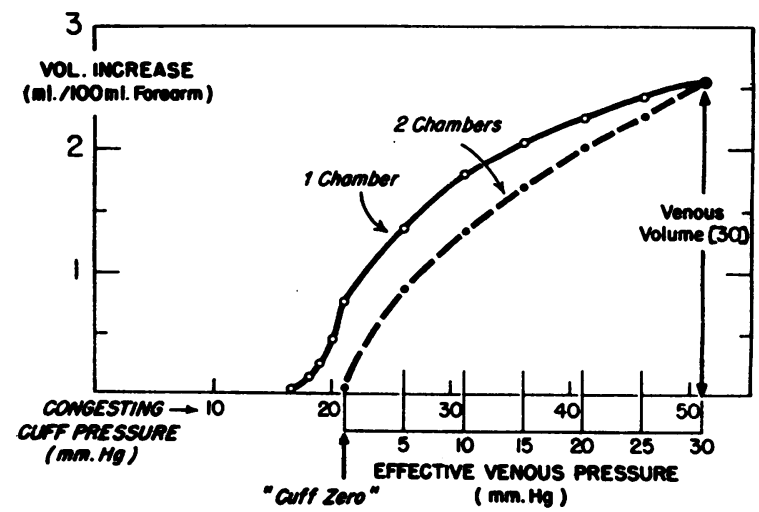

Fig. 2. The Relationship Between Congesting Cuff Pressure, Effective Venous Pressure and Volume Change of the Distal forearm Segment With Water in the Proximal Chamber (Two Chambers) and Without Water in the Proximal Chamber (One Chamber)

"Cuff zero" and venous volume [30] are also indicated. 


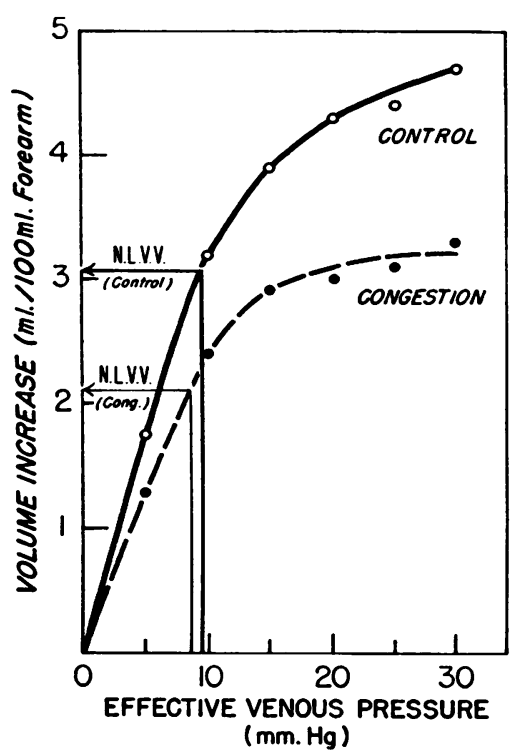

Fig. 3. Venous Pressure-Volume Curves Obtained in a Single Experiment During Control and ConGESTION PERIODS

Concomitantly measured venous pressure is used to deduce natural local venous volume (N.L.V.V.) in each case.

ied in the sitting position in a constant temperature room. They were urged to relax but were not allowed to sleep. The warm environment ranged from $29^{\circ} \mathrm{C}$. to $32^{\circ} \mathrm{C}$. and was continued until digital skin temperature showed no further tendency to rise (usually requiring 30 to 60 minutes). An additional 20 to 30 minutes were utilized to obtain two or three successive venous pressure-volume curves. The cool environment consisted of a room temperature of $18^{\circ} \mathrm{C}$. to $21^{\circ} \mathrm{C}$., associated with a gentle breeze produced by a fan near the subject. The environment was continued until the venous volume [30] values became stable (60 to 90 minutes). Then two or three more pressure-volume curves were obtained. Eleven of the experiments were started in the warm environment and seven were started in the cool environment. Temperature of the water in the plethysmograph was kept at $32^{\circ} \mathrm{C}$. throughout all of these experiments.

The effect of change of local temperature was investigated by maintaining environmental temperature unchanged $\left(29^{\circ} \mathrm{C}\right.$. $)$ and reducing the temperature of the water in the plethysmograph. Three venous pressurevolume curves were obtained at a water temperature of $32^{\circ} \mathrm{C}$., then three more were obtained after water temperature had been reduced to $18^{\circ} \mathrm{C}$.

The effect of congestion of the legs. The same method was used except that the pressure required for the first increment was introduced suddenly so that the initial rate of inscription of the pressure-volume curve of the veins was volume flow of blood. Normal young male subjects were studied on a tilt table in a 30 degree (from hori- zontal) head-up position. Room temperature was maintained at $25^{\circ} \mathrm{C}$. The forearm in the plethysmograph was at the level of the heart. The left antecubital space was at the level of the heart and at the level of the shoulder as well. The membrane of a Statham strain gauge used to measure venous pressure was placed at the level of the right atrium (3). An arterial occluding cuff was inflated on the left wrist during each venous pressure determination. Arterial pressure was determined at five minute intervals by the auscultatory method in the left arm. Mean arterial pressure was considered to be diastolic pressure plus one-third pulse pressure. The rate of the heart was also determined by auscultation at the apex at five minute intervals. Pneumatic congesting cuffs encircled both upper thighs and the left elbow below the needle in the vein. Pneumatic leggings covered the rest of the legs. The cuffs on the upper part of the legs, the cuff on the left forearm and the leggings were inflated from three separate sources. The cuffs on the wrists were inflated from a fourth source. A wide canvas band was used to strap the subject's knees to the table to allow him to relax comfortably. During the initial control period which lasted for 30 to 45 minutes, the leggings and upper leg cuffs were inflated to a pressure which was equivalent to the vertical hydrostatic distance between the knee and the level of the right atrium. Three or more venous pressure-volume curves from the right arm with simultaneous venous pressure from the left arm were recorded during this period. Following this, pressure in the pneumatic leggings was released and simultaneously the three congesting cuffs were inflated to $70 \mathrm{~mm}$. $\mathrm{Hg}$. Then, the pressure-volume curves and venous pressure measurements were repeated at 5 to 10 minute intervals until venous volume [30] became constant. Three more pressure-volume curves were then obtained. Subjects were not allowed to move their legs during the congestion period.

The recovery period was initiated by release of the cuffs on the upper legs and left elbow, followed in 60 seconds by inflation of the leggings and cuffs on the upper legs to the pressure originally used in the control period. Venous pressure-volume curves and simultaneous venous pressures were measured at 5 to 10 minute intervals until the value for venous volume [30] became constant. The last three curves, and their associated venous pressures, mean arterial pressures and pulse rates were averaged to obtain a single value for each function during the control period, the congestion period. and the recovery period.

In separate experiments subjects were studied in the horizontal position utilizing exactly the same procedure as described above.

The venous pressure as measured in the left arm was the natural local venous pressure. This pressure and the concomitantly measured peripheral venous pressurevolume curve were used to deduce the volume of blood present in the venous bed of the limb segment at that pressure. This volume will be referred to hereafter as the natural local venous volume. Thus it was possible to calculate the per cent change in natural local venous 
volume produced by congestion of both legs and the opposite forearm (Figure 3).

All the experiments were analyzed statistically on the basis of paired data. The variability within the control periods or the experimental periods (congesting or cooling) was investigated by determining the differences between each of the values of venous volume [30] and their mean (means only are tabulated in Tables I, II, and III) for that period. Standard error of the mean, standard error of the difference, and probability were then determined for the group of experiments.

\section{RESULTS}

Changes in effective venous pressure and forearm volume resulting from inflation of the proximal cuff by $1 \mathrm{~mm}$. $\mathrm{Hg}$ increments while only the distal chamber of the plethysmograph was filled with water were measured on 5 subjects 11 times. A volume change of the distal forearm segment under these circumstances invariably preceded a change in measured effective venous pressure. This discrepancy was such that it was necessary to inflate the cuff by three to five additional $1 \mathrm{~mm}$. $\mathrm{Hg}$ increments, before a rise in measured effective venous pressure could be induced. Following this and in the same experiment, water was added to the proximal chamber of the plethysmograph. Volume change of that seg- ment was also recorded. The procedure of inflating the proximal cuff by $1 \mathrm{~mm}$. $\mathrm{Hg}$ increments was repeated and it was found that the first change of measured effective venous pressure and the first change of volume of the distal forearm segment then occurred simultaneously. However, a change in volume of the proximal segment invariably preceded a change in its measured effective venous pressure.

Effective venous pressure without pressure in the proximal cuff but with water in the plethysmograph was measured repeatedly in the five subjects. It ranged from 0.5 to $1 \mathrm{~mm}$. $\mathrm{Hg}$ and remained constant throughout each experiment. This effective venous pressure value was not influenced by the water level of the plethysmograph provided the pressure of the water exceeded the natural local venous pressure. Volume change in the proximal chamber always preceded effective venous pressure change by three to five $1 \mathrm{~mm}$. $\mathrm{Hg}$ increments in cuff pressure. Figure 2 illustrates the results of one of these experiments.

Despite the discrepancies in the time of onset of the response in volume and in pressure in the single chamber plethysmograph, change of venous volume in response to a rise of $30 \mathrm{~mm}$. $\mathrm{Hg}$ ef-

TABLE I

Venous volume [30] and blood flow in ml. per $100 \mathrm{ml}$. forearm tissue in the warm and cool environments, with per cent reduction of each and notation as to which environment the subject was first exposed

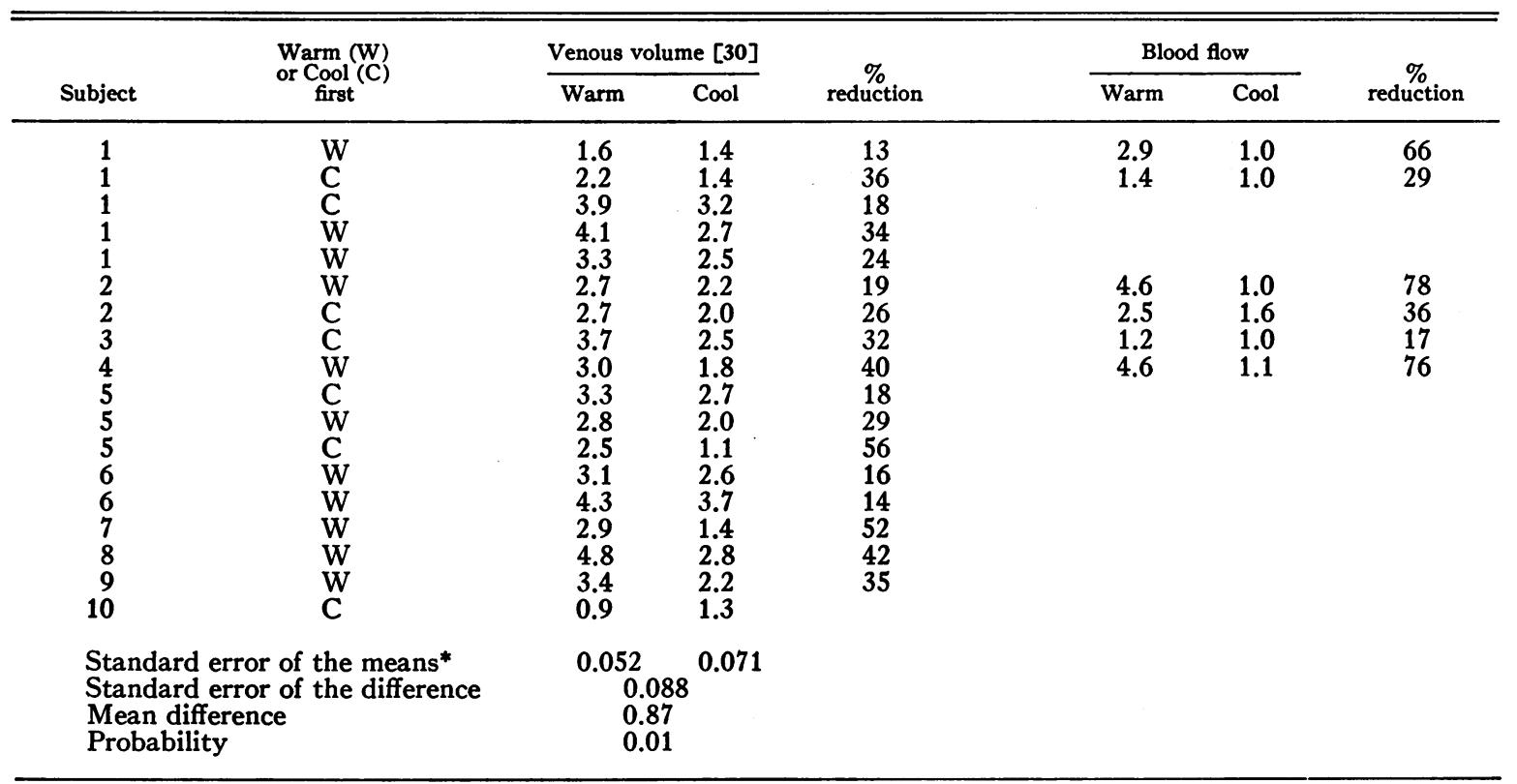

* See text. 
TABLE II

Average venous volume [30] and blood flow in $\mathrm{ml}$. per $100 \mathrm{ml}$. forearm tissue during control (Cl), congestion (Cn), and recovery $(R y)$ periods with per cent decrease of control value during congestion of venous volume [30], and natural local venous volume (N.L.V.V.) per cent decrease of control value during congestion*

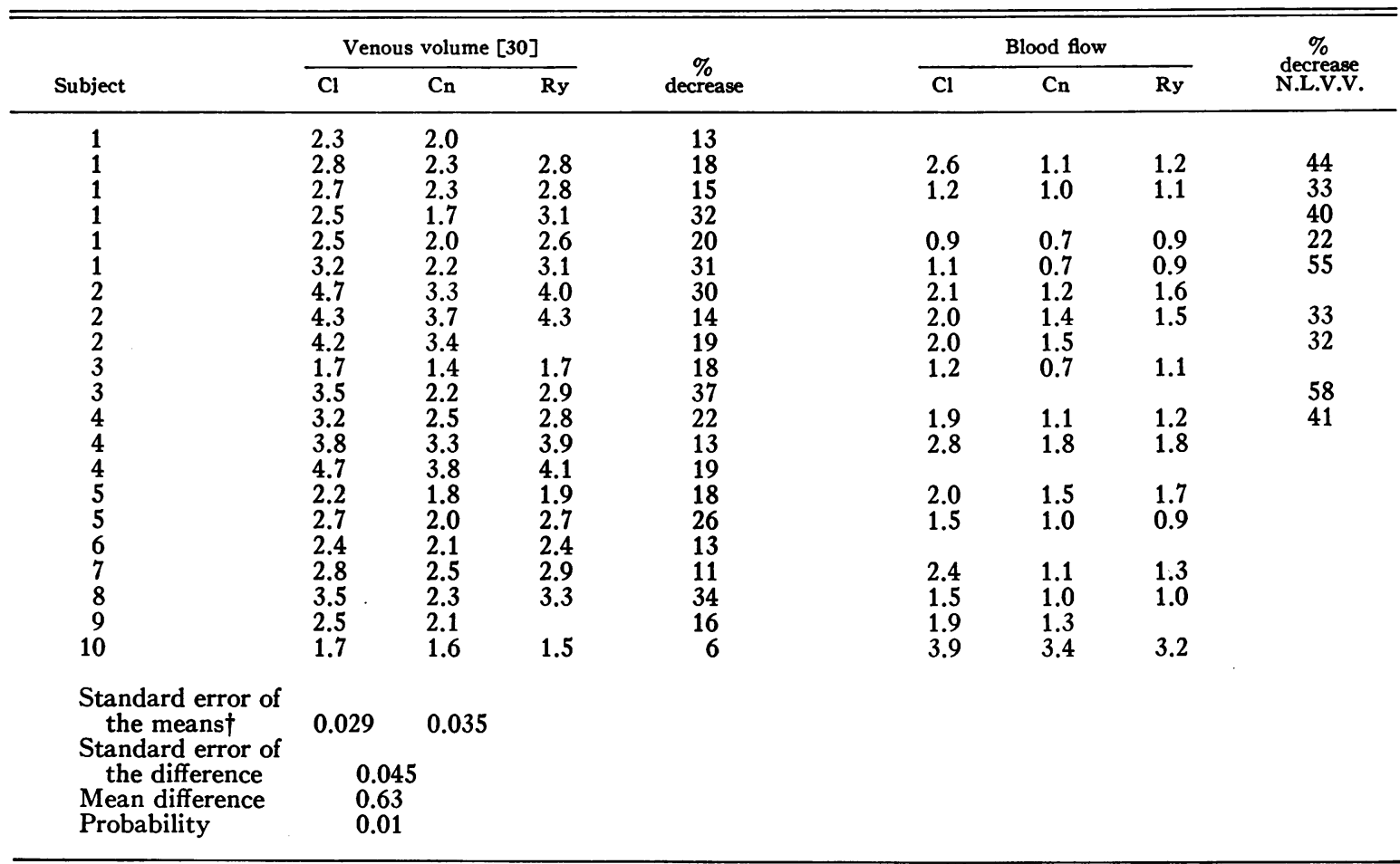

* Thirty degree head-up position.

$\dagger$ See text.

fective venous pressure was essentially the same with or without water in the proximal chamber (Figure 2).

The intravenous infusion of norepinephrine in 3 subjects on 12 occasions resulted in no change in the volume of the forearm when there was no pressure in the proximal cuff. Venous volume [30] decreased in every instance with infusion of norepinephrine. Average control venous volume [30] was $3.2 \mathrm{ml}$. per $100 \mathrm{ml}$. of forearm while venous volume [30] with norepinephrine infusion was $2.4 \mathrm{ml}$. per $100 \mathrm{ml}$. of forearm. In two other subjects and one of the above subjects on five occasions, venous volume [30] was also decreased by norepinephrine infusion but the volume of the forearm without pressure in the proximal cuff was also reduced by 0.3 to $0.7 \mathrm{ml}$. per $100 \mathrm{ml}$. of forearm. Average control venous volume [30] in these experiments was $1.6 \mathrm{ml}$. per $100 \mathrm{ml}$. and average venous volume [30] with infusion of norepinephrine was $1.0 \mathrm{ml}$. per $100 \mathrm{ml}$. of forearm.

\section{The effect of environmental and local cooling}

Ten subjects were studied 18 times in the warm and cool environments. In the cool environment venous volume [30] was decreased in every instance except one. With the exception of that subject, the average decrease in venous volume [30] was 34 per cent and ranged from 13 to 56 per cent (Table I).

TABLE III

Average venous volume [30] and blood flow in $\mathrm{ml}$. per $100 \mathrm{ml}$. forearm tissue during control $(C l)$, congestion $(C n)$, and recovery $(R y)$ periods-Horizontal position

\begin{tabular}{cccccccc}
\hline & \multicolumn{2}{c}{ Venous volume $[30]$} & & \multicolumn{3}{c}{ Blood flow } \\
\cline { 2 - 4 } \cline { 5 - 8 } Subject & $\mathrm{Cl}$ & $\mathrm{Cn}$ & $\mathrm{Ry}$ & & $\mathrm{Cl}$ & $\mathrm{Cn}$ & $\mathrm{Ry}$ \\
\hline 1 & 2.2 & 2.1 & 2.2 & & 1.0 & 0.8 & 0.8 \\
2 & 3.8 & 3.5 & & & 1.7 & 1.2 & \\
4 & 3.1 & 3.2 & & & & & \\
9 & 2.1 & 2.4 & & & 1.7 & 2.0 & \\
9 & 4.0 & 4.1 & & 2.6 & 1.9 & \\
9 & 4.0 & 4.2 & 4.1 & & 4.0 & 2.8 & 2.9
\end{tabular}


Six of these experiments on four subjects were carried out with measurements of blood flow (Table I) on the opposite forearm by the venous occlusion plethysmographic method (4). In the three experiments with the room warm first, blood flow fell as room temperature was being lowered (5 to 10 minutes), while venous volume [30] did not decrease for 30 to 60 minutes. In the three experiments done with the room cool first, venous volume [30] rose during exposure to the warm environment, and in two this occurred 5 to $10 \mathrm{~min}$ utes before blood flow rose. In the third there was no difference in the onset of the responses.

Two subjects were studied four times in the warm environment with the temperature of the water in the plethysmograph first at $32^{\circ} \mathrm{C}$., then at $18^{\circ} \mathrm{C}$. Venous volume [30] was less with cool water in all four experiments by an average of 31 per cent, ranging from 18 to 44 per cent.

\section{The effect of congestion of the legs}

Ten subjects were studied in 21 experiments in the 30 degree head-up position (Table II). Venoconstriction in the forearm in response to pooling of blood in the veins of the limbs occurred in 20 of the 21 experiments. Blood flow determinations during the congestion period were satisfactory in 16 of these experiments. Constriction of the arterioles, indicated by decreased blood flow in the presence of a slight rise in mean arterial pressure, occurred in all 16 experiments. Venous pressure decreased in all of the nine experiments in which it was measured. The decreases at their maximum ranged from 4 to 18 $\mathrm{mm}$. water.

In the 16 experiments in which both constriction of the veins and the arterioles was observed, the onset of constriction of the arterioles occurred within the first 10 minutes of congestion of the limbs and clearly preceded the onset of constriction of the veins in 11. This difference in time of onset ranged from 5 to 35 minutes. The time of onset of these two phenomena could not be distinguished in four experiments, and constriction of the veins clearly preceded constriction of the arterioles in one. The congestion period was 45 to 90 minutes in duration.

During the recovery period venous volume [30] measurements were satisfactory in $17 \mathrm{ex}$ - periments and blood flow measurements were satisfactory in 14 experiments. Dilatation of the veins relative to the state of constriction observed during the congestion period occurred in all 17 of these experiments. Dilatation of the arterioles occurred in 11 before termination of the experiment, while the constriction of the arterioles induced during the congestion period persisted throughout the recovery period in the remaining three experiments. In 10 of these 11 experiments dilatation of the veins started before dilatation of the arterioles began. In one case there was no apparent difference in the time of onset of dilatation of the veins and the arterioles.

Venous pressure measurements were satisfactory in eight recovery periods of these experiments. In seven of these, sudden reapplication of compression in the leggings resulted in overshoot of venous pressure relative to the subsequent resting level. This overshoot ranged from 7 to 24 $\mathrm{mm}$. of water and lasted from 1 to 3 minutes.

The average pulse rate during the control period was 72 per minute. Pulse rate rose in every experiment during the congestion period to an average maximum level of 80 (the subject with vasovagal syncope is excluded). The average basal level in the recovery period was 70 . Average mean arterial pressure was 102, 104, and 104 $\mathrm{mm} . \mathrm{Hg}$, respectively, during these three periods.

The percentile reduction in natural local venous volume during the period of congestion was computed in the nine experiments in which venous pressure was measured. It ranged from 22 to 58 per cent and averaged 39.8 per cent. The value exceeded 32 per cent in all cases except one, which was 22 per cent. It was of interest to note that fainting occurred only in this subject. His pulse rate was less than 40 during this episode, suggesting a vasovagal response. The remaining subjects had no serious symptoms during congestion but did complain variously of warmness, sweating, listlessness and annoyance, in that order of frequency.

Six experiments were done in the horizontal position (Table III) without venous pressure measurements. Constriction of the veins occurred in two of these subjects to a mild degree, while no response was evident in the remaining four experiments. Pulse rate, blood flow and arterial pressure were little affected by congestion 
of the limbs of subjects in the horizontal position. The congestion period was maintained for 60 to 90 minutes in these experiments.

\section{DISCUSSION}

The method utilized for these studies is a further modification (5) of a previously described method (6). The further modification was done in order to approximate more closely in vivo the ideal in vitro circumstances necessary for measuring the pressure-volume characteristics of a distensible system (7), in this case the veins of the forearm. This ideal situation would have as its starting point a completely empty system at zero or even negative pressure and permit one to raise the pressure in convenient steps while measuring the simultaneously induced volume change with each step. However, it is impractical to use a bloodless venous bed at zero effective pressure in vivo because of its attendant physiologic (circulatory arrest) and technical (pressure plethysmography) disadvantages. Therefore, it becomes necessary to demonstrate that changes of volume of the undistended veins induced by a strong venoconstrictor stimulus are small or at least predictable. The points along the venous pressure-volume curve are valid only if it can be demonstrated that associated changes of pressure and volume occur simultaneously.

The phenomenon of volume increase preceding pressure increase when a single chamber plethysmograph was used was probably due to early congestion of the poorly pressurized cone of tissue at the proximal end of the plethysmograph (8). A pressure cone occurs between two segments of forearm subjected to different pressures, with the base at the level of the change in pressure and the apex toward the higher of the two pressures. Thus, there would be no cone within the distal end of the plethysmograph, although there would be a cone beneath the proximal end of the arterial occlusion cuff distal to the plethysmograph.

The total measured increase in volume of the venous system of the forearm ( $\mathrm{ml}$. per $100 \mathrm{ml}$. of tissue per $30 \mathrm{~mm}$. Hg increase in effective venous pressure) was not altered significantly by the presence or absence of the proximal chamber of the plethysmograph. Thus studies of venous volume [30] utilizing a single chamber plethysmo- graph (5) would not be invalidated by the findings described herein. On the contrary, the larger single chamber plethysmograph has the advantage of smaller variability of results when one subject is to be compared with another (due presumably to the smaller variability from one subject to another of the bone to soft tissue ratio of a longer segment) and is preferable for this type of study. Since the additional refinement of a proximal chamber allows inscription of an accurate pressure-volume curve, local venous volume at low venous pressures may be accurately predicted. The two-chamber plethysmograph, therefore, appears to be superior to the single-chamber plethysmograph for study of acute responses of veins when a subject is used as his own control during a single continuous experiment.

The forearm venous pressure-volume curve is a graphic presentation of the volume of blood that a venous system of $100 \mathrm{ml}$. of forearm tissue will accept with a given change of effective venous pressure. Constriction of the smooth muscle of the veins results in a less distensible system. In addition, venous pressure-volume curves indicate the magnitude of the decrease in local venous volume, at a given effective venous pressure, which has been caused by venoconstriction if the volume of the veins at their lowest effective venous pressure $(0.5$ to $1.0 \mathrm{~mm} . \mathrm{Hg})$ is unaltered by the venoconstriction. When venoconstriction is intense or occurs in an already constricted venous bed, the initial volume of the veins at this low effective venous pressure may decrease. In this case, decrease in venous volume at a given effective venous pressure would be greater than that indicated by the venous pressure-volume curve which has been observed. Moderate venoconstriction of a previously dilated venous bed, induced by infusion of norepinephrine, did not alter the volume of the veins at low effective venous pressure. Leonard and Sarnoff have observed that an unstretched helical section of vein shortens when exposed to a constrictor agent (9). The explanation for the apparently contradictory observations may be that dilated veins at low effective venous pressures may be elliptical in crosssection and may tend to become circular with constriction. This geometric change would allow the cross-sectional area (thus volume of the tube) to remain unchanged despite a decrease in 
circumference of the tube. Once the circular configuration was reached, further constriction would result in a decrease in volume even at low effective venous pressure. The observation that venous beds with a low control venous volume [30] tended to diminish in volume at low effective venous pressure after infusion of norepinephrine is consistent with this hypothesis. The length, width and thickness of the unstretched venous system cannot be determined in vivo by presently available methods; thus, its length-tension relationships relative to resting length cannot be calculated. This fact does not alter the contribution of the venous pressure-volume curve to a more complete understanding of the physiology of the peripheral veins.

\section{The effect of environmental and local cooling}

The responses of the veins to cooling of the environment and to cooling of the extremity locally indicate that it is necessary to control these temperatures during experiments designed for study of the veins. The difference in rate of response (though the direction was the same) of the arterioles and veins is further evidence that the method measures the characteristics of the veins, independently of arteriolar changes.

Greenfield and Patterson (10) found that high environmental temperatures produced no further venodilatation when the experiment was started in a comfortable environment. Although their method was more analogous to the pressure plethysmographic approach (11) rather than to the method presently described, the resulting data can probably be compared at least qualitatively with those obtained by methods reported here. Results obtained with these methods with body warming are essentially the same (12). Further dilatation of veins does not occur despite the marked arteriolar dilatation that occurs with body heating. (This is another example of a difference in the response of the arterioles and veins.) Unlike the arterioles, the peripheral veins appear to be maximally dilated when the subject is comfortably warm.

\section{The effect of congestion of the legs}

There is little doubt that the peripheral venous system participates actively in the complex vascu- lar responses to a diminution of effectively circulating blood volume (13-16). Further questions are: 1) What is the time-course relationship of the venoconstriction and the arteriolar constriction? 2) What is the degree of venoconstriction in terms of the venous pressure-volume curve and the resultant change in natural local venous volume?

The intensity of the stimulus employed in these experiments depends upon the volume of blood removed from the parts of the vascular bed not subjected to congestion and the position of the subject. It may be categorized further by the severity of symptoms and signs induced by the congestion of the limbs.

Ebert and Stead (17) measured the volume of blood pooled in both legs and one arm of supine normal subjects by cuffs on these extremities inflated to diastolic pressure. The volume changes obtained were probably similar to those produced in the experiments reported here despite the difference in position of the subjects, since pneumatic leggings were used to prevent dependent pooling of blood during the control periods in the experiments here reported. They found that the blood volume normally present in the head, trunk and one arm was reduced by an average of $720 \mathrm{ml}$. or 15 per cent, with a range of 13 to 18 per cent.

The signs and symptoms of the subjects and the observations of Ebert and Stead (17) indicate that the intensity of the stimulus to the cardiovascular system was of the order of that produced by an acute reduction of effectively circulating blood volume of 500 to $1,000 \mathrm{ml}$. when the subject is in the head-up position.

It has been suggested (18) that under most circumstances venous and arteriolar responses occur simultaneously. This implies that the response of veins and arterioles is one of a parallel increase in tone, the degree and rapidity of which depends upon the stimulus. However, under the circumstances of the experiments described here, rigid parallelism of these responses in the forearm was usually absent. With the onset of limb congestion arteriolar constriction began almost at once while venoconstriction not only began later, but required more time to reach maximum intensity. Relief from congestion resulted in just the opposite response inasmuch as arteriolar constriction persisted after remission of venoconstriction. 
These differences in rate of response suggest that initial moderate reduction of effectively circulating blood volume of an uptilted subject represents only a mild stimulus to the forearm veins. On the contrary, the same stimulus appeared adequate to induce an immediate response of the forearm arterioles and thus might be considered to be a relatively more intense stimulus to the peripheral arterioles.

Limb congestion in the horizontal position failed to induce significant peripheral vascular responses in these experiments and has failed to alter cardiac output in other experiments (19). Limb congestion in the 30 degree upright position resulted in a dissociation of the venous and arteriolar responses. It is reported that sudden tilting to the upright position causes an immediate (within 50 seconds) constrictor response of a single superficial vein (15). These observations suggest that in man the peripheral arterioles respond to increasing reductions of effectively circulating blood volume at a lower level than do the peripheral veins.

The per cent reduction of natural local venous volume of the right arm induced by pooling of blood was much greater (40 per cent) than the presumed reduction of the vascular volume of the head, trunk, and right arm (15 per cent). This finding implies that the veins of uncongested skeletal muscles did not merely reduce their volume by the amount of blood that was removed but actually tended to move the remaining blood volume centrally. That is, the amount of venoconstriction in the periphery exceeded that of more - centrally placed veins.

Sudden restoration of blood volume following congestion of the legs caused a sharp rise in venous pressure to a point above the level that it was to assume later in the recovery period. The finding of venous pressure "overshoots" suggested that the venoconstriction induced by congestion of the limbs persisted for a few moments after relief from congestion.

\section{SUMMARY AND CONCLUSIONS}

1. A new two-chamber plethysmographic method for accurately recording the peripheral venous pressure-volume curve in man is described.

2. Using this method, peripheral venoconstriction is found to occur in a cool environment, or after locally cooling the part in the plethysmograph.

3. Arterial constriction commonly precedes venoconstriction on going from a warm to a cool environment while venodilatation usually precedes arteriolar dilatation on going from a cool to a warm environment.

4. Congestion of the legs in the 30 degree (from horizontal) head-up position usually resulted in prompt arteriolar constriction and venous pressure reduction followed by peripheral venoconstriction (in the forearm).

5. Relief of congestion usually caused in sequence: 1) venous pressure "overshoot," 2) venodilatation, and 3 ) arteriolar dilatation.

6. Natural local venous volume of the forearm veins was reduced by two and one-half times the presumed percentile reduction in effectively circulating blood volume. This finding suggests that after congestion of the lower limbs the remaining blood volume was moved centrally by venoconstriction in the periphery which was more intense than that in the central veins.

7. The venous pressure overshoot following restoration of effectively circulating blood volume to "normal" suggested that the venoconstriction that had taken place in response to a reduction of blood volume had persisted for a short time after its restoration.

\section{REFERENCES}

1. Wilkins, R. W., and Eichna, L. W., Blood flow to the forearm and calf. I. Vasomotor reactions: role of the sympathetic nervous system. Bull. Johns Hopkins Hosp., 1941, 68, 425.

2. Cooper, K. E., and Kerslake, D. McK., An electrical volume recorder for use with plethysmographs (abstract). J. Physiol., 1951, 114, 1 P.

3. Winsor, T., and Burch, G. E., The plebostatic axis and plebostatic level. Proc. Soc. Exper. Biol. \& Med., 1945, 58, 165.

4. Wood, J. E., Litter, J., and Wilkins, R. W., The mechanism of limb segment reactive hyperemia in man. Circ. Research, 1955, 3, 581.

5. Wood, J. E., Litter, J., and Wilkins, R. W., Peripheral venoconstriction in human congestive heart failure. Circulation, 1956, 13, 524.

6. Litter, J., and Wood, J. E., The venous pressurevolume curve of the human leg measured in vivo (abstract). J. Clin. Invest., 1954, 33, 953.

7. Ryder, H. W., Molle, W. E., and Ferris, E. B., Jr., The influence of the collapsibility of veins on venous pressure, including a new procedure for 
measuring tissue pressure. J. Clin. Invest., 1944, 23, 333.

8. Landowne, M., and Katz, L. N., A critique of the plethysmographic method of measuring blood flow in the extremities of man. Am. Heart J., 1942, 23, 644.

9. Leonard, E., and Sarnoff, S. J., Effect of aramineinduced smooth muscle contraction on length-tension diagrams of venous strips. Circ. Research, 1957, 5, 169.

10. Greenfield, A. D. M., and Patterson, G. C., On the capacity and distensibility of the blood vessels of the human forearm. J. Physiol., 1956, 131, 290.

11. Litter, J., and Wood, J. E., The volume and distribution of blood in the human leg measured in vivo. I. The effects of graded external pressure. J. Clin. Invest., 1954, 33, 798.

12. Litter, J., and Wood, J. E. Unpublished observations.

13. Wilkins, R. W., Haynes, F. W., and Weiss, S., The rôle of the venous system in circulatory collapse induced by sodium nitrite. J. Clin. Invest., 1937, $16,85$.

14. Landis, E. M., and Hortenstine, J. C., Functional significance of venous blood pressure. Physiol. Rev., 1950, 30, 1.

15. Page, E. B., Hickam, J. B., Sieker, H. O., McIntosh, H. D., and Pryor, W. W., Reflex venomotor activity in normal persons and in patients with postural hypotension. Circulation, 1955, 11, 262.

16. Alexander, R. S., Venomotor tone in hemorrhage and shock. Circ. Research, 1955, 3, 181.

17. Ebert, R. V., and Stead, E. A., Jr., The effect of the application of tourniquets on the hemodynamics of the circulation. J. Clin. Invest., 1940, 19, 561.

18. Gollwitzer-Mier, K., Venensystem und Kreislaufregulierung. Ergebn. d. Physiol., 1932, 34, 1145.

19. Warren, J. V., Brannon, E. S., Stead, E. A., Jr., and Merrill, A. J., The effect of venesection and the pooling of blood in the extremities on the atrial pressure and cardiac output in normal subjects with observations on acute circulatory collapse in three instances. J. Clin. Invest., 1945, 24, 337. 